\title{
DESIGN OF THE POWER OF AN ELECTRIC LIFTING MOTOR FOR A SINGLE GIRDER BRIDGE CRANE WITH A 500 KG LOAD CAPACITY
}

\begin{abstract}
An electric hoist could be considered as the most important component of an electric overhead crane. Electric hoists are material handling equipment used for lifting, lowering, and transporting materials and products. They are powered by an electric motor and have a controller to adjust the lifting parameters. Three-phase induction motors are most often used as electric lifting motors for bridge cranes. This paper concerns the design of the power of the electric lifting motor for an electric hoist of the single girder bridge crane with the $500 \mathrm{~kg}$ load capacity. It represents the design of the electric lifting motor according to a commonly used scheme for the design of electric motors, from the power at a uniform load to the relative load of the motor. Based on the input data, the necessary motor parameters are calculated using Microsoft Excel. The main parameter is the static power of the motor, the calculated value of which is $0.823 \mathrm{~kW}$. Based on the value of this power, a three-phase induction motor $1.1 \mathrm{~kW}$, MS90-4 is selected. This electric lifting motor is suitable for the above-mentioned bridge crane, as it meets the condition of torque overload.
\end{abstract}

Keywords: Induction motor, electric hoist, motor power, bridge crane, lift, torque

\author{
Denis Molnár ${ }^{1}$ \\ ${ }^{1}$ Faculty of Mechanical Engineering, Department of Transport and Handling Machines, University of \\ Žilina, Univerzitná 8215/1,010 26 Žilina; + 42141513 2659; denis.molnar@fstroj.uniza.sk \\ Miroslav Blatnický ${ }^{2}$ \\ ${ }^{2}$ Faculty of Mechanical Engineering, Department of Transport and Handling Machines, University of \\ Žilina, Univerzitná 8215/1, 01026 Žilina; + 42141513 2659; miroslav.blatnicky@fstroj.uniza.sk \\ Ján Dižo ${ }^{3}$ \\ ${ }^{3}$ Faculty of Mechanical Engineering, Department of Transport and Handling Machines, University of \\ Žilina, Univerzitná 8215/1,01026 Žilina; + 42141513 2560; jan.dizo@fstroj.uniza.sk
}

\section{Introduction}

The hoist can be considered as one of the most essential components of the bridge crane system, because it ensures the lifting and lowering of the load. The lifting mechanism (Fig.1) of the crane lifts and lowers the load by means of a drum or a lifting wheel in which a chain or a wire rope is wound. Electric hoists can be designed to use chain or wire rope and use an electric motor to turn gears located inside the hoist that lift or lower the load. Electric hoists are controlled by pushbutton pendant or radio controls. Electric hoists are typically hard-wired into the crane's electrification system (Close, 2017).

The motor in the lifting process is constantly in different states, such as a power-up, outage, start, brake and reverse state in order to meet the operating characteristics of the crane. The motor is variously exposed to the load at all stages. In view of these facts, an overload capacity of the lifting motor must be strong and sufficient to withstand greater overload and mechanical shock (Dongqui, 2017). Most electric hoists are designed to withstand hazardous and high-temperature environments. Electric hoists have faster operation than other types of hoists. Electric wire rope hoists, like electric chain hoists, are equipped with a hoist motor with an integrated braking system. They also utilize a series of gears inside a gearbox that amplify the transmitted torque from the motor. The concentrated force from the gearbox is transmitted to a spline shaft. The spline shaft then rotates the winding drum. As the wire rope is pulled to vertically displace the load, it is wound around the winding drum (Industrial, 2021).

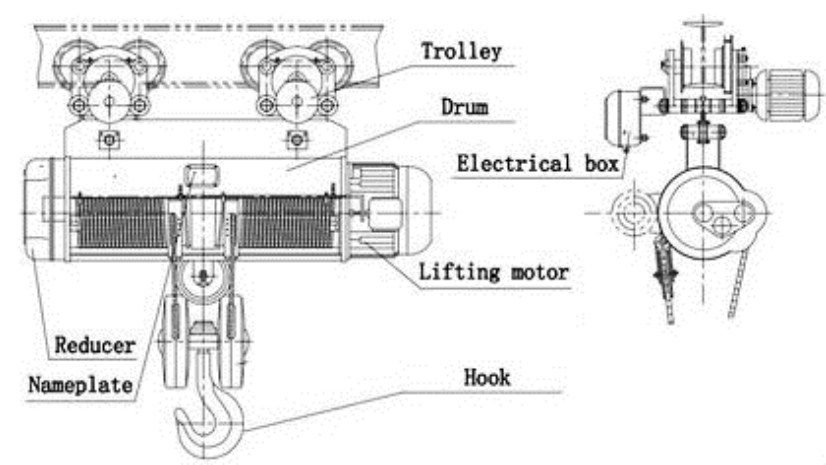

Fig. 1. Components of an electric hoisting mechanism

(Nucleon, 2021)

The hoist drive on a crane is hard to implement because it must operate smoothly over a wide range of speeds to lift up or lower the hook at controlled speeds regardless of the load. The motoring torque with a relatively flat speed/torque characteristic must be provided by the drive during the lifting process to prevent excessive speed change from heavy-load to light-hook conditions. In practice, induction motors are most often used to drive electric hoists. The lifting (induction) motor is equipped with an electromagnetic brake, which plays an important role in lowering the load (Crowders, 1980). 


\section{Induction motor}

The induction or asynchronous motor is a type of AC motor, which have two basic parts stator and rotor. The stator is a stationary part whereas the rotor is the rotating part. The winding placed on the stator acts as the primary winding and rotor as the secondary winding (Wat Electrical, 2019). The supply of energy to the rotor is ensured by electromagnetic induction from the rotating magnetic field of the stator winding (Diyoke, 2016). The advantages of asynchronous motors are good operating characteristics, a wide power range of feasibility and a simple design that increases their operational reliability (Voženílek, 2011). The rotor of the induction motor can be in the form of a squirrel cage rotor or wound type rotor. Almost $90 \%$ of induction motors are equipped with squirrel cage rotor. The construction of these motors is robust and simple. The squirrel cage rotor comprises of cylindrical laminated core with evenly spaced bars along the periphery, whereby these bars are placed into semiclosed circular slots. Bars are made of aluminium and copper. These bars are connected at ends mechanically and electrically by the use of end rings. The rotor is mounted on the shaft using bearings on both ends (Fig.2). Skewed slots ensure smooth and ample torque, increase resistance of rotor since the length of the rotor bar conductors is increased (Alkhadim, 2020, Mansour, 2020).

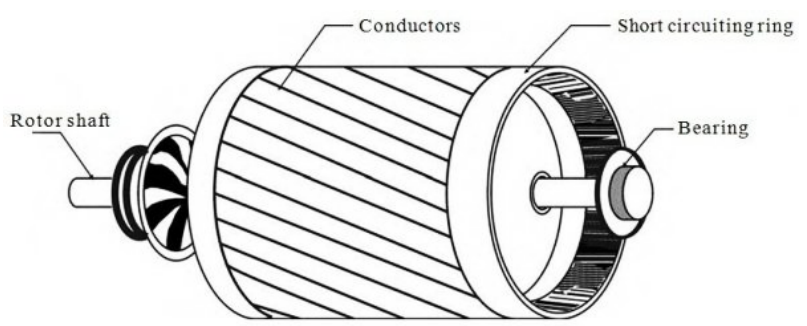

Fig. 2. Squirrel cage rotor components (Theengineeringprojects, 2021)

Squirrel cage type is more common compared to the wound rotor type due to:

- Robust, as no brushes, no contacts on the rotor shaft.

- Simple in construction and easy to manufacture.

- Almost maintenance-free, except for bearing and other mechanical parts.

- High efficiency as rotor has very low resistance and thus low copper loss (Alkhadim, 2020).

The wound rotor (Fig.3) has a set of windings on the rotor slots which are not short circuited, but they are terminated to a set of slip rings. These are helpful in adding external resistors and contactors. The rotor is also skewed as in squirrel cage rotor. The number of poles on which the rotor is wound is the same as in the case of the stator. There are several semi-closed slots on the outer periphery of rotor. The winding of rotor is connected in a star form (Alkhadim, 2020, Mansour, 2020).

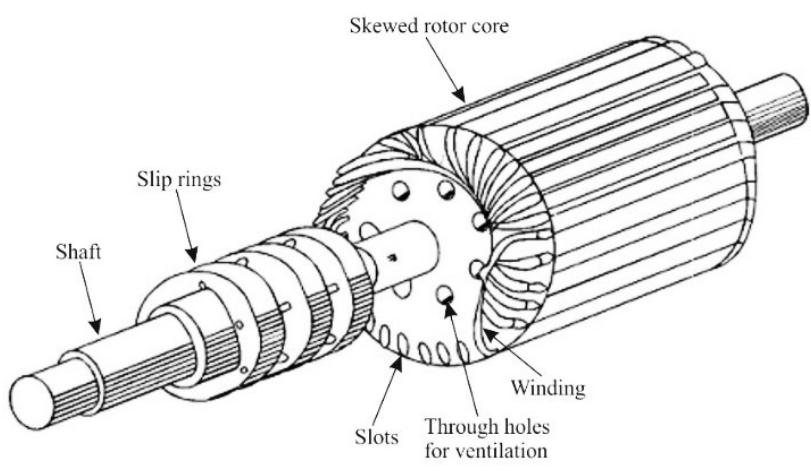

Fig. 3. Wound rotor components (EEEGUIDE, 2021)

Induction motors are produced in two versions, like as single-phase or three-phase. The single-phase induction motors are usually constructed in small sizes (Mansour, 2020). The three-phase induction motor with electromagnetic brake is commonly used for electric hoist.

The working principle of three-phase induction motor is based on electromagnetic induction. The stator of the motor consists of overlapping winding offset by an electrical angle of $120^{\circ}$. When the primary winding or the stator is connected to a three phase AC source, the rotating magnetic field which rotates at the synchronous speed is created. The mutual force action between the rotating field and the rotor currents creates a moment which, according to Lenz's law, acts against the cause of its origin, i.e. against the mutual movement of the stator field and the conductors in the rotor. As the speed of the rotor increases, its relative speed with respect to the rotating field decreases and thus the frequency of the rotor current also decreases. As a result of the generated torque, the rotor starts to accelerate in the same direction as the stator field rotates. Thus, from the working principle of three phase induction motor, it may be observed that the rotor speed should not reach the synchronous speed produced by the stator (Electrical4you, 2020, Uhlír 2002, Voželínek 2011).

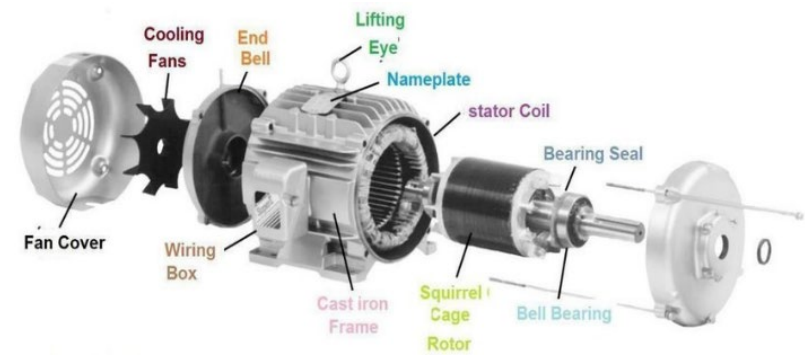

Fig. 4. Components of the Squirrel cage induction motor (Alkhadim, 2020)

\section{Design of the lifting motor power}

The lifting motor is an essential part of the electric overhead crane. The three-phase AC asynchronous motor (hereinafter referred as motor) is usually used as lifting motor. One of the fundamental parts of designing process of the lifting motor is to design a suitable motor power with regard to the maximum capacity of the overhead crane. Therefore, the design of the lifting motor power for a single-girder bridge crane with the load capacity of 500 
$\mathrm{kg}$ will be performed. The design of the electric motor power generally proceeds according to the scheme in Fig. 4.

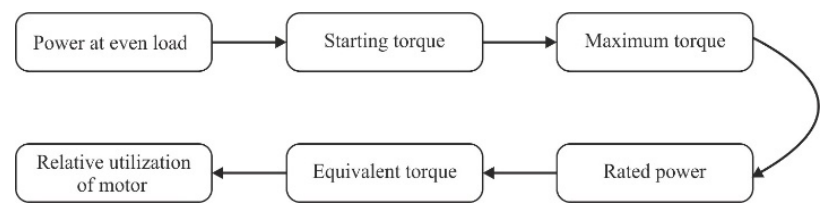

Fig. 5. A scheme of the design of the electric motors

The operation of the lifting motor is considered to be irregular, because the motor is forced to work with different loads, which vary depending on the weight of the load. The operation of the motor can be divided into phases, when the motor accelerates, when it lifts or lowers the load at a constant speed and when it decelerates or brakes. The required power of the electric motor at constant lifting can be determined according to (1):

$$
P_{s}=\frac{v_{l} \cdot \sum m_{i} \cdot g}{\eta_{t} \cdot 1000}
$$

where:

$P_{s}-$ motor power $[\mathrm{kW}]$

$v_{l}$ - lifting speed $\left[\mathrm{m} \cdot \mathrm{s}^{-1}\right]$

$g$ - gravitational acceleration $\left[\mathrm{m} \cdot \mathrm{s}^{-2}\right]$

$\eta_{t}-$ total efficiency [-]

There is the sum of the weights of the lifted parts $\sum m_{i}$ in equation (1). This part of the equation represents the sum of the weights of the load and all the equipment that will be lifted together with the load. It is the sum of the weights of the rope, hook, spreader bars, grabber, and other means of fastening (2).

$$
\sum_{i=1}^{n} m_{i}=Q+m_{r}+m_{h}+\ldots+m_{n}
$$

The total mechanical efficiency $\eta_{t}$ can be determined as the product of the efficiency of the pulley $\eta_{p}$ and the efficiency of the gears $\eta_{i}$ (3):

$$
\eta_{t}=\eta_{p} \cdot \eta_{i}
$$

The mechanical efficiency of the hoist $\eta_{h}$ can be determined for $n_{p}$ pulleys as (4):

$$
\eta_{h}=\eta_{1} \cdot \frac{\left(1-\eta_{1}^{n_{p}}\right)}{n_{p} \cdot\left(1-\eta_{1}\right)}
$$

Efficiency of plain bearing is $\eta_{p}=0.96$ and efficiency of rolling bearing is $\eta_{r}=0.98$. The efficiency of transmissions of electric motor is determined as the product of the efficiencies of the individual transmission elements. The transmission elements include gears that correct the rpm of the electric motor to the rpm required to achieve the specified lifting speed. The lifting speed $v_{l}$ is one of the variable parameters, the choice of which directly affects the required power of the lifting motor. Also, the lifting speed can be selected according to the lifting height (Kul'ka, 2017). The torque of motor is usually specified by the manufacturer but can also be determined from equation (5).

$$
M_{\eta_{l}}=\frac{P_{\eta} \cdot 1000}{2 \cdot \pi \cdot n_{l}}
$$

where:

$M_{r_{l}}$-rated motor torque $[\mathrm{N} \cdot \mathrm{m}]$

$P_{r_{l}}$ - rated motor power $[\mathrm{kW}]$

$n_{l}-\mathrm{rpm}$ of the lifting motor $\left[\mathrm{s}^{-1}\right]$

\subsection{Starting torque of the lifting motor}

The motor must be checked for torque overload at lifting speeds greater than $0.08 \mathrm{~m} . \mathrm{s}^{-1}$. The check is based on the moment required to start the motor at the lifting speed in time $t_{a}$. The starting torque $M_{\text {start }}$ is determined from (6):

$$
M_{\text {start }}=M_{s t_{l}}+M_{a t_{l}}+M_{a \eta_{l}}
$$

The static moment of the load $M_{s t_{l}}$ is determined according to the equation (7):

$$
M_{s t_{l}}=\frac{D_{d} \cdot \sum m_{i} \cdot g}{2 \cdot i_{h} \cdot \eta_{t} \cdot i_{l}}
$$

where:

$D_{d}$ - diameter of the drum [m]

$\sum m_{i}$ - sum of the weights of the lifted parts $[\mathrm{kg}]$

$g$ - gravitational acceleration $\left[\mathrm{m} \cdot \mathrm{s}^{-2}\right]$

$i_{h}$ - gear ratio of the hoist [-]

$\eta_{t}-$ total efficiency [-]

$i_{l}-$ transmission ratio between the motor and the lift [-]

The gear ratio of the hoist $i_{h}$ is determined according to the number of pulleys $n_{p}$ and the arrangement of the hoist. The transmission ratio between the motor and the lift $i_{l}$ is determined from the ratio of motor rpm $n_{l}$ and drum $\operatorname{rpm} n_{d}(10)$

$$
\begin{aligned}
& i_{l}=\frac{n_{l}}{n_{d}} \\
& n_{d}=\frac{v_{l}}{\pi \cdot D_{d}}
\end{aligned}
$$




$$
i_{l}=\frac{n_{l} \cdot \pi \cdot D_{d}}{v_{l}}
$$

The moment of accelerating forces with the translating effect $M_{a t_{l}}$ is determined as (11):

$$
M_{a t_{l}}=M_{s t_{l}} \cdot \frac{a_{l}}{g}
$$

According to STN 27 0601, the acceleration of lift must be in the interval $a_{l} \in\langle 0.2-0.3\rangle \mathrm{m} \cdot \mathrm{s}^{-2}$. The moment of accelerating forces with the rotating effect $M_{a r_{l}}$ is determined by the equation (12):

$$
M_{a \eta_{l}}=\alpha \cdot I_{m} \cdot \frac{2 \cdot \pi \cdot n_{l}}{t_{a_{l}}}
$$

where:

$$
\begin{aligned}
& \alpha-\text { coefficient from rotating parts }[-] \\
& I_{m}-\text { moment of inertia }\left[\mathrm{kg} \cdot \mathrm{m}^{2}\right] \\
& n_{l}-\operatorname{rpm} \text { of the lifting motor }\left[\mathrm{s}^{-1}\right] \\
& t_{a_{l}}-\text { starting-up time }[\mathrm{s}]
\end{aligned}
$$

The motion of the hoist's lift is considered to be uniformly accelerated or uniform motion. The starting-up time can therefore be determined as (13):

$$
t_{a_{l}}=\frac{v_{l}}{a_{l}}
$$

The coefficient $\alpha_{l}$ takes into account the influence of the rotating parts of the motor except the rotor and is considered:

- $\quad \alpha_{l}=1.2[-]$ for devices with one brake disc,

- $\alpha_{l}=1.4[-]$ for devices with two brake disc.

The moment of inertia $I_{m}$ is given in the motor tables. Sometimes it is stated in the form of the so-called GD - quadrate, according to which the moment of inertia can be determined (14).

$$
I_{m}=\frac{G \cdot D_{l}^{2}}{4}
$$

The resulting starting torque can then be expressed in summary by substituting the individual moments into equation (6) and thus equation (15) is obtained (Kul'ka, 2017):

$$
\begin{aligned}
M_{\text {start } l} & =\frac{D_{d} \cdot \sum m_{i} \cdot g}{2 \cdot i_{h} \cdot \eta_{t} \cdot i_{l}} \cdot\left(1+\frac{v_{l}}{g \cdot t_{a_{l}}}\right)+ \\
& +\frac{\alpha_{1} \cdot G \cdot D_{l}^{2} \cdot \pi \cdot n_{l}}{2 \cdot t_{a_{l}}}
\end{aligned}
$$

\subsection{Torque overload capacity}

The asynchronous motor can be overloaded, and it can produce $1.8-3.2$ times more torque in the short term than the torque resulting from the nominal power of the motor. Thanks to this feature, the motor with less rated power than the maximum required power can be selected. The manufacturer states in the tables the coefficient of torque overload, which indicates how many times the motor can be overloaded. The torque overload is given by the ratio (16):

$$
\xi=\frac{M_{\max }}{M_{n}}
$$

The torque $M_{\max }$ is considered as the maximum possible torque that a motor with rated overload $\xi$ can generate. Each torque required in operation must therefore be less than $M_{\max }$. The coefficient $\xi$ is determined according to the load factor $\varepsilon$ :

- $\varepsilon=25 \%$ then $\xi=2.1[-]$

- $\varepsilon=40 \%$ then $\xi=2.5[-]$

- $\varepsilon=60 \%$ then $\xi=2.9[-]$ (17).

The rated motor torque $M_{n}$ must satisfy condition

$$
M_{n} \geq \frac{2 \cdot M_{\text {start }}}{\xi+1.1}
$$

If the selected motor does not meet the condition (17), a more powerful motor according to the manufacturer's catalogue must be selected (Kul'ka, 2017).

\subsection{Determination of the equivalent torque}

The load on the motor causes it to warm up depending on the amount of torque required. Thus, the equivalent torque represents such torque whose constant action on the motor during one working cycle produces the same thermal effects as the real moments acting during one working cycle. If the crane operates in an irregular operating mode, the calculation of the equivalent torque is based on one operating cycle at full load. In general, the equivalent torque $M_{e}$ is determined by the equation (18):

$$
M_{e}=\sqrt{\left(\frac{\sum_{i=1}^{n} M_{i}^{2} \cdot t_{i}}{T}\right)}
$$

where:

$M_{i}$ - torque of an individual phase $[\mathrm{N} \cdot \mathrm{m}]$

$t_{i}$ - duration of the phase [s]

$T$ - period of duty cycle $[\mathrm{s}]$

The duty cycle of the bridge crane lift can be divided into 3 phases. The first is the start of the lift, when the 
starting torque acts for the time $t_{a_{l}}$. The second phase is uniform lifting, where the load is lifted at a constant speed and the motor exerts a constant torque. The last phase is braking (Kul'ka, 2017). The duty cycle is shown in Fig. 6.

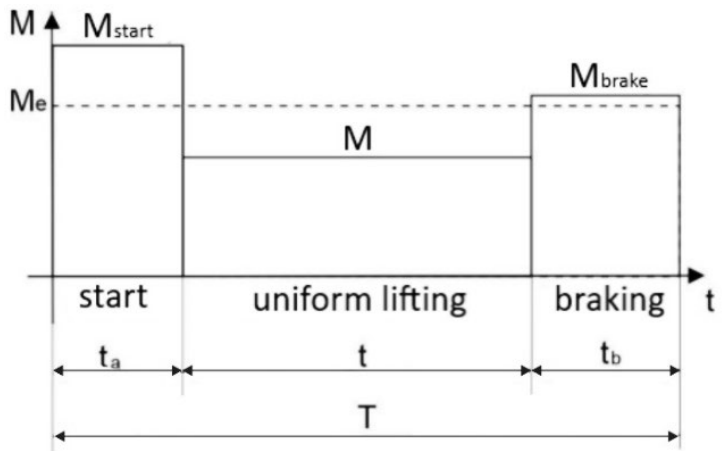

Fig. 6. A duty cycle of crane

Based on the equation (18), the equivalent torque for such a duty cycle is determined by equation (19):

$$
M_{e_{l}}=\sqrt{\frac{M_{s t a r t_{l}}^{2} \cdot t_{a_{l}}+M_{s t_{l}} \cdot t_{s t_{l}}+M_{b r a k e_{l}}^{2} \cdot t_{b_{l}}}{t_{a_{l}}+t_{s t_{l}}+t_{b_{l}}}}
$$

\subsection{Relative utilization of the lifting motor}

In operation, cranes usually lift loads of various weights. This means that the lifting motor is forced to work with a variable load. Therefore, it is necessary to determine the relative motor utilization $\mu_{l}$. This indicates the ratio between the required motor torque at full load $M_{\text {full }}$ when lifting a load with the maximum permissible weight and the torque at part load $M_{\text {partial }}$ (20).

$$
\mu_{l}=\frac{M_{\text {full }}+M_{\text {partial }}}{2 \cdot M_{\text {partial }}}
$$

For bridge crane lifting motors $\mu_{z}=0.40-0.75$ (-) is applied. Coefficient $v$ is determined according to coefficient $\mu$ using Tab. 1 .

Table 1. Values of relative utilization depending on type of a mechanism

\begin{tabular}{|l|l|l|l|l|l|l|}
\hline \multicolumn{3}{|c|}{ Mechanism } & \multicolumn{3}{c|}{$\mu[-]$} \\
\hline \multirow{2}{*}{ Lifting } & \multicolumn{2}{l|}{ Cranes with hook } & \multicolumn{3}{c|}{$0.40-0.70$} \\
\hline \multirow{2}{*}{ Travel } & \multicolumn{2}{|l|}{ Crane cats (hoists) } & \multicolumn{3}{c|}{$0.65-0.75$} \\
\cline { 2 - 7 } & \multicolumn{2}{|c|}{ Travel of crane bridge } & \multicolumn{3}{c|}{$0.75-0.90$} \\
\hline Relative utilization $\mu[-]$ & 0.55 & 0.6 & 0.7 & 0.8 & 0.9 & 1.0 \\
\hline Coefficient $v[-]$ & 0.74 & 0.74 & 0.76 & 0.83 & 0.91 & 1.0 \\
\hline
\end{tabular}

\subsection{Braking of the motor lift}

When designing the lifting device, it is also necessary to design the amount of torque that the brake (usually electromagnetic) will overcome. The brake overcomes during braking the same torques as the motor during lifting process, according to equation (15). However, the real braking torque $M_{\text {brake }_{l}}$ must be increased by the braking coefficient $k_{b}$ (21).

$$
\begin{aligned}
M_{\text {brake }_{l}} & =k_{b} \cdot \frac{D_{d} \cdot \sum m_{i} \cdot g}{2 \cdot i_{h} \cdot \eta_{t} \cdot i_{l}} \cdot\left(1+\frac{v_{l}}{g \cdot t_{a_{l}}}\right)+ \\
& +\frac{\alpha_{1} \cdot G \cdot D_{l}^{2} \cdot \pi \cdot n_{l}}{2 \cdot t_{a_{l}}}
\end{aligned}
$$

The coefficient $k_{b}$ is chosen according to the lifting class of the crane according to Tab. 2 (Kul'ka, 2017).

Table 2. Value of the braking coefficient for individual lifting

\begin{tabular}{|l|l|}
\hline \multicolumn{2}{|c}{ classes } \\
\hline Lifting class & Braking coefficient [-] \\
\hline A & $\mathrm{k}_{\mathrm{b}}=1.5$ \\
\hline B & $\mathrm{k}_{\mathrm{b}}=1.75$ \\
\hline C & $\mathrm{k}_{\mathrm{b}}=2.0$ \\
\hline
\end{tabular}

\section{Calculation of a bridge crane lifting motor}

The calculation and subsequent selection of the lifting motor is performed for the single girder bridge crane with a load capacity of $500 \mathrm{~kg}$. This calculation is processed in Microsoft Excel according to the above procedure using the above equations and conditions. The input data listed in Tab. 3. are important for the correct calculation of the lifting motor.

Table 3. Input parameters for calculation of the crane lifting

\begin{tabular}{|l|l|l|l|}
\hline Input data & Notation & Value & Unit \\
\hline Load capacity & $\mathrm{Q}$ & 500 & $\mathrm{~kg}$ \\
\hline Lifting speed & $\mathrm{v}_{\mathrm{l}}$ & 5 & $\mathrm{~m} \cdot \mathrm{min}^{-1}$ \\
\hline Lifting speed & $\mathrm{v}_{\mathrm{l}}$ & 0.083 & $\mathrm{~m} \cdot \mathrm{s}^{-1}$ \\
\hline Lifting acceleration & $\mathrm{a}_{\mathrm{l}}$ & 0.3 & $\mathrm{~m} \cdot \mathrm{s}^{-2}$ \\
\hline Acceleration time & $\mathrm{t}_{\mathrm{al}}$ & 0.278 & $\mathrm{~s}$ \\
\hline Number of pulleys & $\mathrm{n}_{\mathrm{p}}$ & 1 & {$[-]$} \\
\hline Gear ratio of hoist & $\mathrm{i}_{\mathrm{h}}$ & 1 & {$[-]$} \\
\hline Efficiency of one pulley & $\eta_{1}$ & 0.96 & {$[-]$} \\
\hline Efficiency of gears & $\eta_{\mathrm{i}}$ & 0.9 & {$[-]$} \\
\hline Gravitational acceleration & $\mathrm{g}$ & 9.80665 & $\mathrm{~m} \cdot \mathrm{s}^{-2}$ \\
\hline Crane class & $\mathrm{H}_{\mathrm{i}}$ & 1 & {$[-]$} \\
\hline Diameter of rope drum & $\mathrm{D}_{\mathrm{d}}$ & 0.08 & $\mathrm{~m}$ \\
\hline
\end{tabular}

It is necessary to determine the values of individual coefficients for the calculation. These values are given in Tab 4.

Table 4. Used factors and coefficients in calculation

\begin{tabular}{|l|l|l|l|}
\hline Factors and coefficients & Notation & Value & Unit \\
\hline Coefficient of rotating parts & $\alpha_{\mathrm{l}}$ & 1.2 & {$[-]$} \\
\hline Load factor from the load weight & $\gamma_{\mathrm{lo}}$ & 1.3 & {$[-]$} \\
\hline Load factor from the self-weight & $\gamma_{\mathrm{g}}$ & 1.1 & {$[-]$} \\
\hline Dynamic lifting factor & $\delta_{\mathrm{h}}$ & 1.217 & {$[-]$} \\
\hline
\end{tabular}

Based on the input data, the necessary parameters are calculated, and these are listed in Tab. 5. 
Table 5. Calculated parameters

\begin{tabular}{|l|l|l|l|}
\hline Parameter & Notation & Value & Unit \\
\hline Lifting weight & $\mathrm{m}_{\mathrm{i}}$ & 870.155 & $\mathrm{~kg}$ \\
\hline Efficiency of hoist & $\eta_{\mathrm{h}}$ & 0.96 & {$[-]$} \\
\hline Total efficiency & $\eta_{\mathrm{t}}$ & 0.864 & {$[-]$} \\
\hline Static motor power & $\mathrm{P}_{\mathrm{s}}$ & 0.823 & $\mathrm{~kW}$ \\
\hline
\end{tabular}

Based on the calculated parameters, a three-phase induction motor $1.1 \mathrm{~kW}, \mathrm{MS} 90-4$ is selected as the suitable motor. The motor parameters are listed in Tab. 6 .

Table 6. Parameters of the selected lifting motor

\begin{tabular}{|l|l|l|l|}
\hline \multicolumn{4}{|c|}{ Three-phase induction motor 1.1 $\mathbf{k W}$ MS90-4 } \\
\hline Parameter & Notation & Value & Unit \\
\hline Static motor power & $\mathrm{P}_{\mathrm{s}}$ & 0.82 & $\mathrm{~kW}$ \\
\hline Rated power & $\mathrm{P}_{\mathrm{r}}$ & 1.10 & N.m \\
\hline GD - quadrate & $\mathrm{GD}^{2}$ & 0.0015 & $\mathrm{~kg} . \mathrm{m}$ \\
\hline Rpm of motor & $\mathrm{n}_{\mathrm{l}}$ & 1390 & $\mathrm{~min}^{-1}$ \\
\hline Moment of inertia & $\mathrm{I}_{\mathrm{m}}$ & 0.00037 & $\mathrm{~kg} \cdot \mathrm{m}^{2}$ \\
\hline Rated torque & $\mathrm{M}_{\mathrm{r}}$ & 7.56 & N.m \\
\hline Coefficient of rated overload & $\xi$ & 2.10 & {$[-]$} \\
\hline
\end{tabular}

Subsequently, it is necessary to check the motor for torque overload by determining the starting torque according to equation (15) and to check if the motor meets the condition of torque overload (17). The results are listed in Tab. 7.

Table 7. Calculated torques of motor

\begin{tabular}{|l|l|l|l|}
\hline Parameter & Notation & Value & Unit \\
\hline Static torque & $\mathrm{M}_{\text {stl }}$ & 5.654 & $\mathrm{~N} \cdot \mathrm{m}$ \\
\hline Moment of sliding parts & $\mathrm{M}_{\text {atl }}$ & 0.173 & $\mathrm{~N} \cdot \mathrm{m}$ \\
\hline Moment of rotating parts & $\mathrm{M}_{\text {arl }}$ & 0.0581 & $\mathrm{~N} \cdot \mathrm{m}$ \\
\hline Starting torque & $\mathrm{M}_{\text {startl }}$ & 5.885 & $\mathrm{~N} \cdot \mathrm{m}$ \\
\hline
\end{tabular}

After substituting the values into condition (17), it can be stated that the three-phase induction motor $1.1 \mathrm{~kW}$, MS90-4 (Fig. 7) meets the condition of torque overload for the specified parameters. Thus, it is suitable for use as the lifting motor for the single-girder bridge crane with the load capacity of $500 \mathrm{~kg}$.

$$
\begin{aligned}
& 7.56 \geq \frac{2 \cdot 5.885}{2.1+1.1} \\
& 7.56 \mathrm{~N} \cdot \mathrm{m} \geq 3.678 \mathrm{~N} \cdot \mathrm{m}
\end{aligned}
$$

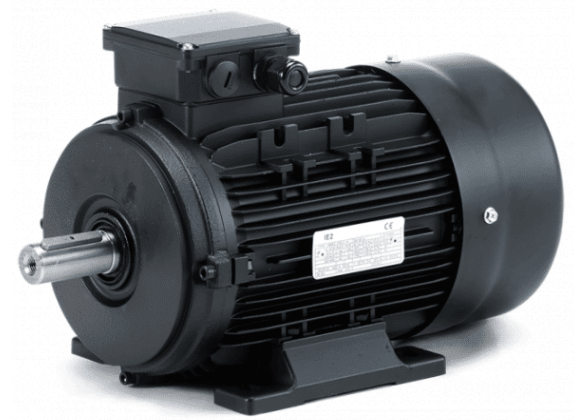

Fig. 7. A three-phase induction motor $1.1 \mathrm{~kW}, \mathrm{MS} 90-4$ (Vyboelectric 2021)

\section{Conclusion}

One of the aims of this paper was to approach the use of induction motors to drive crane lifting mechanisms, such as bridge crane electric hoists. The three-phase asynchronous motor with electromagnetic brake is the most commonly used lifting motor for electric hoists. The main goal was to design the lifting motor, its power, for the single-girder bridge crane with the $500 \mathrm{~kg}$ load capacity. Based on the input data, the motor parameters were calculated using the Microsoft Excel program. The most important parameter for choosing the lifting motor was the static power of the motor. The value of the static motor power was $0.823 \mathrm{KW}$. Based on this power value, the three-phase induction motor $1.1 \mathrm{~kW}$, MS90-4 was selected. Finally, it was necessary to check this lifting motor for torque overload. Since the rated motor torque of $7.56 \mathrm{~N} \cdot \mathrm{m}$ is greater than the calculated starting torque of $5.885 \mathrm{~N} \cdot \mathrm{m}$ i.e., the torque overload condition is met, it can be concluded that the selected three-phase induction motor is suitable for use as the lifting motor for the abovementioned bridge crane.

\section{Acknowledgement}

This work was supported by the Cultural and Educational Grant Agency of the Ministry of Education of the Slovak Republic in the project No. KEGA 023ŽU-4/2020: Development of advanced virtual models for studying and investigation of transport means operation characteristics.

\section{References}

Alkadhim, S. A. S. 2020 Three-phase Induction Motor: Types and Structure. In:SSRN (Social Science Research Network), online, 11 p. Cited 22.10.2021 Online: https://papers.ssrn.com/sol3/papers.cfm?abstract_id=3647 425

Close, M. 2017 Overhead Crane Hoist Types and Design: Manual, Electric, and Air. Cited 15.10.2021 Online: https://www.mazzellacompanies.com/learningcenter/overhead-crane-hoist-types-design-wire-ropechain-manual-electric-air/

Crowder, R. M., Smith, G.A. 1980 Induction Motors for Crane Applications. In:IEE Journal on Electric Power Applications. Vol. 2, No. 6 (1980), online, p. 194-198. Cited 16.10.2021 Online: https://www.researchgate.net/publication/224398774_Ind uction_Motors_for_Crane_Applications

Diyoke, G. C., Okeke, C., Aniagwu, U. 2016 Different Methods of Speed Control of Three-PhaseAsynchronous Motor. In: American Journal of Electrical and Electronic Engineering. Vol. 4, No. 2 (2016), online, p. 62-68. Cited 19.10.2021 Online: http://pubs.sciepub.com/ajeee/4/2/3

Dongqui Group. 2017 The Selection of Crane Hoisting Motor Mechanism. Cited 15.10.2021 Online: https://www.craneskit.com/crane-hoisting-motor.html

EEEGUIDE. 2021 Construction of Induction Motor. Cited 25.10.2021 Online: https://www.eeeguide.com/construction-of-inductionmotor/

Electrical4you. 2020 Three Phase Induction Motor Definition \& Working Principle. Cited 24.10.2021 Online: 
https://www.electrical4u.com/working-principle-of-threephase-induction-motor/

Kul'ka, J., Mantič, M., Puškár, M. 2017 Žeriavy mostového typu. /Bridge cranes/. Košice: Technická univerzita v Košiciach, 220 p., ISBN 978-80-553-2908

Mansour, F. 2020 Induction Motors: Construction, Principle of Operation, Power and Torque Calculations, Characteristics and Speed Control. Cited 22.10.2021 Online: https://www.researchgate.net/publication/343546075

Nucleon. 2021 Wire Rope Electric Hoist Parts. Cited 19.10.2021 Online: http://www.nucleoncranegroup.com/wire-ropeelectric-hoist-parts.html

STN 270601 Bezpečnostná technika. Kladkostroje elektrické. Všeobecné požiadavky. /Safety technique. Electrical pulley tackles. General requirements/. Approved, Effective 11. 1987. Bratislava: SÚTN, 1987. 8 p.

Theengineeringprojects. 2021 Squirrel Cage Induction Motor. Cited 22.10.2021 Online: https://www.theengineeringprojects.com/2016/10/squirrelcage-induction-motor.html

Uhliŕ, I. 2002 Elektrické stroje a pohony. /Electric machines and drives/. Praha: Vydavatelství ČVUT, 120 p., ISBN 8001024822.

Voženílek, P., Novotný, V., Mindl, P. 2011 Elektromechanické měniče. 2. vyd. /Electromechanical converters. 2. ed./. Praha: České vysoké učení technické v Prahe, 219 p., ISBN 978-80-01-04875-7.

Vyboelectric. 2021 Katalóg 3-fázových elektromotorov. /Catalogue of 3-phase induction motors/. Cited 26.10.2021 Online: https://www.elektromotoryprevodovky.sk/obchod/elektromotor-ms-90-4-1-1kw/

Wat Electrical. 2019 What is an Induction Motor - Principle, Working \& Types. Cited 18.10.2021 Online: https://www.watelectrical.com/what-is-an-inductionmotor-principle-working-types/
Industrial Quick Search. 2021 Electric Hoist. Cited 16.10.2021 Online: https://www.iqsdirectory.com/articles/electrichoist.html 